\title{
The Danger of being a Young Female Migrant: A Case Study Female Refugees in Musina Town in South Africa
}

\author{
Mamadi Khutso, Rapholo Selelo Frank and Ramoshaba Dillo Justin
}

\author{
Department of Social Work, University of Limpopo, Private Bag X1106, 0727, Sovenga, South Africa
}

\begin{abstract}
Several studies show that international migrants across the globe extremely face challenges upon their arrival in the host countries. This constant influx of international population movement is driven by factors such as escaping from poverty, seeking better livelihoods, or escaping from political upheavals and civil strife, such as wars. There have been several studies in South Africa that generally explored challenges faced by the international migrant youth but not necessarily on the gendered nature of migration. This study argues that migration affects males and females inversely. Thus this study aimed to contextually explore the danger of being a young female migrant by following a qualitative research approach using female refugees in Musina town as a case study. Nine participants were purposively and conveniently selected and semi-structured face-to-face interviews with open-ended questions were followed to collect data that is analysed thematically in this paper. The Nvivo software was used to manage and organise data. Findings reveal that young female migrants face challenges from the cross-bordering where they are at risk of being raped. Findings further show that upon their arrival in South Africa, female young migrants face challenges such as exclusion from basic health care services due to lack of immigration documents, sex work, and exploitation by local citizens as well as victimization by the police. The security at border posts should thus be tightened and the defence forces should jointly work with the police officials to deport female migrant youth who migrate illegally and stakeholders in South Africa should run educational programmes where the illegal immigrants would be educated about the risks of cross-boarding to South Africa without legal immigration permits.
\end{abstract}

Keywords: International female migrant youth, Illegal Migration, South Africa.

\section{INTRODUCTION}

Currently, South Africa has an entry of both international and cross-border immigrants who migrated to the country for better employment opportunities and education, and in some cases to offer cheap labour (Bisrat, 2014). Nonetheless, Shea (2009) explains that South Africa's economic stability and proximity to other African countries make it an attractive atmosphere for most students, professionals, and businesspeople. Most of these immigrants have come with high expectations to take advantage of the opportunities they aspire to and those presented to them by the host country. Several studies reveal that unfortunately, immigrants upon their arrival in the country face several challenges for their sustainable livelihoods (Mcdonald, 2000; Pasura, 2008; SerumagaZake, 2017; Statistics-SA, 2018; Rapholo, 2020). Additionally, several authors including Tati (2010) and Van Tonder and Soontiens (2013) argue that most young people migrate out of their home countries expecting to pursue studies and find better employment opportunities. Although their actual experiences are different from what they expected, most of them meet their expectations, but this process is where the challenge lies. Most migrants are faced with adverse situations such as rape and victimisation by the police

*Address correspondence to this author at the Department of Social Work, University of Limpopo, Private Bag X1106, 0721, Sovenga, South Africa; Tel: (+2715) 268 3876; E-mail: frank.rapholo@ul.ac.za and are as well excluded from accessing healthcare services. From the above assertions, the study has therefore sought to explore the danger of being a young female migrant in Musina town in the Limpopo province, which is approximately $18 \mathrm{~km}$ away from Beitbridge border post which divides South Africa and Zimbabwe.

\section{RESEARCH PROBLEM}

South Africa has a long history of cross-border migration from surrounding countries and is the main migrant-receiving country in the region. Migration to South Africa is often a household 'poverty reduction strategy' (Black, Crush, Peberdy, Ammassari, Hilker, Mouillesseaux, Pooley and Rajkotia, 2006) and therefore forms part of a survival strategy for some households who depend on the remittances sent by those who have migrated. Consequently, these young female migrants are met with unpleasant circumstances and are exposed to danger such as rape and being exposed to sex work as a means to make ends meet to support both themselves and their families. Like men, women are now turning to migration to meet their economic obligations. They are migrating to different parts of the continent (Africa), particularly to South Africa in search of paid employment in the face of deteriorating living and working conditions in their countries of origin, and in some cases, instability of marriage (Oppong, 1997). Foreign countries, including South Africa, offer African female migrant youth various 
attractions, including a wide range of opportunities for education, training, and employment, and give women a sense of privacy and personal freedom. However, in their search for independence and autonomy through migration in the host country, young migrant women are exposed to a dangerous livelihood such as rape and exploitation while illegally crossing the border, as well as having to sell sex in exchange for money to survive. Such dangers are experienced either upon their arrival or during their stay in the host country. Female migrants also face various challenges in destination countries such as exclusion from basic healthcare services, exploitation by local citizens as well as being victimised by the police. In support of this, Shai and Mothibi (2015) note that most immigrants who live in informal settlements are characterized by social exclusion, discrimination as well as high levels of poverty, finding it hard to earn an income.

\section{Aim of the Study}

The study aimed to contextually explore the danger of being a young female migrant in South Africa.

\section{Theoretical Framework}

This study was guided by the narrative theory which was developed by Michael White and David Epston in the 1970s. This theory is primarily about how accounts of what happened to particular people in particular circumstances can be so common and so powerful at once with particular consequences. Narrative theory is also about how stories help people make sense of the world, and also how people make sense of the stories. According to Bal (2004), the narrative theory is adopted when one puts forward information about occurrences that have occurred, may or may not occur. This theory was useful as it gave an insight and an understanding in terms of what are the dangers of being a young female migrant in host countries, as these female migrants were able to own up to their own experiences and narrate their stories and the dangers they are faced with and continue to be exposed to in their everyday lives as migrants in a foreign country. In this study, the narrative theory has helped shape the stories of female migrants in South Africa exactly as they have experienced them indicating the type of dangers and ill-treatments they are exposed to merely based on being an illegal female migrant while they are trying to secure better livelihoods in the host country.

\section{Ethical Consideration}

Ethical clearance was acquired from Turfloop Research and Ethics Committee (TREC) of the
University of Limpopo with project number TREC/155/ 2020: PG; permission to conduct the research was granted by Musina Local Municipality in the Limpopo Province, and also by churches that manage shelters for refugees in Musina. The aim of this study as well as the voluntary nature of respondent's participation was clearly explained to the respondents; after respondents verbally agreed to participate in the study, participants as well signed consent forms. Confidentiality in the study was ensured by keeping the names and identities of the respondents private.

\section{METHODOLOGY}

The qualitative design was the most appropriate for this study. This method is suitable for understanding people's behaviours and perceptions (Hammarberg, Kirkman \& de Lacey, 2016). It allowed the researchers to obtain detailed information on the dangers of being a young female migrant in a foreign country and also presented an opportunity for female migrants to give indepth information on the dangerous experiences they have encountered as well as risky situations they have been exposed to. Qualitative approaches are about understanding the social life as well as the meaning that people ascribe to their everyday life (de Vos, Strydom, Fouche, \& Delport, 2011). To pursue the aim of the study, the researchers followed an exploratory case study design as a research design for this paper to explore the dangers of being a young female migrant in Musina, South Africa. A case study research design allowed the researchers to engage in the female migrants' daily activities and experiences in the host country to gain an intimate understanding of their social worlds and to examine the meanings they give to such experiences. Purposive sampling was used to purposively select female migrant youth in Musina to share their experiences of the ill-treatments and exploitations they are faced within South Africa as young female migrants while they are in transit from their home countries and during their stay in South Africa. Miles and Huberman (2014) state that, in purposive sampling, an individual is chosen because s/he illustrates some feature or quality. Primary data was collected through face-to-face interviews using semi-structured interviews. Through the semistructured interviews, the opportunity to have a deeper understanding of the respondents' experiences, probe, and ask follow-up questions was explored. Data were analysed thematically in this study through the help of the Nvivo Software. To ensure the quality of the findings, credibility, conformability, transferability, and dependability were followed. Credibility through prolonged engagement, member checking, and peer 
examination was ensured, and field notes were written directly after each interview with each female migrant for auditing purposes to ensure the conformability of the findings. Data was correctly coded for dependability purposes. Data was gathered from a small number of respondents until saturation $(n=09)$.

\section{DISCUSSION OF FINDINGS}

\section{Demographic Details of Participants}

This study involved nine female migrant youth who come from Zimbabwe. All the nine (09) migrant youth hailed from Zimbabwe, and possible domination of Zimbabwean participants in this study could be that Musina Town is close to the Beit Bridge border post which divides Zimbabwe and South Africa. However, it cannot be concluded that migrants from other African countries in South Africa do not face challenges in the host country, however, the study purposefully focused on only those who were available at the shelter and willing to participate. The respondents ranged between the ages of 18-35 years of age. The following themes emerged after the interviews with the young female migrants:

\section{Theme 1: Rape}

Participants in the study have indicated how they are often exposed to dangerous situations in the host country. One participant mentioned that being a female migrant youth looking for survival in South Africa is very risky as opposed to when you are a man. Unlike men, migrant women are not able to protect themselves from male employers who take advantage of them. Another participant mentioned that some male employers ask for sexual favours before they could give them a job, and they believe this is because employers are aware of their desperation for employment. One participant mentioned that after you are done cleaning for the male employers, they will ask you for sex and promise to give you a lot of money, and after that, they don't keep their promise and they ask you to leave. The researchers are of the view that being a desperate young migrant woman in South Africa attracts a lot of human rights violations and harassment from local citizens who know these migrants are without protection and will not report such incidents to the police.

In support of the above, one participant echoed:

"There are many risks if you're a woman like me looking for a job, if you want a job they say first you must sleep with me then I will give you a job and sometimes take the money and all your belongings, so it's tough for a female."

Another participant added:

"Hhmm the condition was so harsh; you find some other time men take advantage. Like some other time, I had an incident, a man came here and said he wants me to wash his clothes but when we went to his place, he just said no I want you to entertain me, that they want to use you, have sex with you."

In the same wavelength, another participant said:

"You find that some other time they just say after you're done with the work I want to sleep with you I will pay you extra money and if you deny it, it won't be good. Sometimes they won't pay you that money you worked for, or even harass you. After you do what they ask, they don't pay you, and you find that you can walk from town up to here on foot, with no transport, no money worked for. And it is risky for you to tell someone, so I just keep quiet."

It can be noted from the study findings that female migrant youth feel unsafe as far as seeking employment is concerned. They experience harassment in that they are sometimes asked for sexual favours to get employment. Findings also reveal that seeking employment for female migrant youth is risky as compared to their male counterparts as they could get raped while trying to secure jobs. In support, Hiralal (2017) notes that migrant women have difficulty in securing formal employment, and are subject to harassment, sexual abuse, and patriarchal oppression. Collectively, these factors have, to some extent, exacerbated violence against some women immigrants. It is quite unfortunate that when they experience such kinds of abuse at the hands of men, young migrant women are left without any form of assistance, particularly if they are without legal documentation. It can thus be concluded that young female migrants are in constant danger and at high risk of sexual exploitation in their everyday lives, they easily fall prey to men who sexually exploit them.

\section{Theme 2: Exclusion from Basic Health Care Services}

Participants in the study have highlighted that because of their lack of documentation, they often find 
it difficult to access basic health care services in the host country. As a result of their lack of legal documents, migrant female youth in South Africa are faced with a lot of negative treatment from healthcare professionals when they visit public clinics and hospitals. They have often turned away, asked to produce legal documents upfront, called all sorts of negative names. Healthcare workers use young female migrants' undocumented status as an excuse as to why they cannot offer medical treatment to them and are eventually turned away without a care. One participant further indicated that the healthcare workers often make them wait longer on the queues while they attend to South Africans first, even when the migrants were the first to arrive at the clinic. The researchers have noted that documentation plays a major role in determining migrants' access to the country's basic services such as health care. Young female migrants are denied access by their non-national status. Crush and Tawodzera, 2014; Human Rights Watch [HRW], 2015; Human Sciences Research Council [HSRC], 2010; Randolph, 2012 assert that, since refugees are often considered as "others" or "outsiders" who are entering the country to access the limited resources destined to the legitimate citizens, they are mostly impacted by limited access to health and social services in destination countries. Additionally, Belvedere, Pigou, and Handmaker (2001) and Crush and Tawodzera, (2014) argue that to date, South Africa is known for institutionalised medical xenophobia and discriminatory practices against foreign migrants. Xenophobic views and related practices in the health system have also been blamed as yet another challenge in accessing healthcare services by refugees.

In support of the above, one respondent said:

"Ah, sometimes there is another good nurse at the clinic, they treat me nicely. When I'm going another day there is another nurse who tells me you won't get treatment here because you are foreigners, sometimes maybe the security at the clinic will tell us you don't have a passport or id or you're foreigners you will not be attended here and then we come back.."

Another respondent echoed:

"That one eish it's too much, especially in clinics. When you go there the nurses will shout at you especially when you don't have a passport, but as to me I have a passport but they will also shout and they will say go back to Zimbabwe. Sometimes we don't go there, we just sleep when we are not feeling well, and we will be fine."

In the same wavelength, one participant said:

"There are different issues that we meet. Sometimes other nurses shout at us and tell me I will help you later after the South African first, we must help the South African first then we will call you. Maybe you're going it is six o'clock in the morning and you will come back at two o'clock."

It can be noted from the study findings that documentation plays a big role in determining migrants' access to South Africa's public healthcare services. Being a migrant alone, whether documented or undocumented, puts one at risk of being denied treatment by healthcare professionals, leaving them unattended and without care. Despite policies in South Africa that assure free medical care to everyone, including migrants, health staff finds it difficult to incorporate and implement such policies in practice, merely because of their cultural insensitivity and their dislike for migrants. The Constitution of the Republic of South Africa is interpreted within the National Health Act (2004) to include provisions relating to access to public healthcare services for all in South Africa, with no mention of nationality or legal status. However, its interpretation is less inclusive within implementation guidelines and practice. Consequently, migrants are disadvantaged by this fact and end up without medical care. The right to access health care services is constitutionally guaranteed for everyone living in South Africa and by the National Health Care Act as well as the Refugee Act (HRW, 2015; Republic of South Africa, 1998). Female migrant youth have continually had to deal with rejection, non-acceptance, and discrimination, even in the hands of government officials. Adjai and Lazaridis (2013) argue that national identity in the new democratic South Africa has been built on citizenship. Access to state and public resources is determined by citizenship and protected by legal instruments. The researchers are of the view that such negative treatments of migrants are initiated by racially insensitive health workers who hold a strong belief that migrants are depleting the already scarce resources only meant for local South African citizens. 


\section{Theme 3: Sex Work}

Some participants mentioned involvement in sex work as a strategy to make ends meet, particularly because they are struggling to find decent jobs and support their families. They have also indicated that their decision to resort to sex work was sole because they were forced by circumstances and we're not proud of the work they are doing, but because of the difficult conditions in South Africa, they have to earn a living to support themselves. It was further highlighted by some participants that they are very much aware of the risks and dangers involved in the kind of work they do, but they are willing to risk everything for as long as they would not sleep on an empty stomach. Some participants indicated that even though they did not join the sex industry, they know of their migrant friends who are also involved in sex work. As a result of the difficulty in finding employment, migrant women end up getting involved in sex work in destination countries. Richter, Luchters, Ndlovu, Temmerman, and Chersich (2012) argue that cross-border migrant women involved in sex work are normally heads of households supporting an average of five persons in their families. Such vulnerabilities may explain, in part, why many of the migrant women do not like to label themselves as sex workers, preferring instead to show that their selling of sex is mere because of the pressure and the economic demands that they are faced with, such as having to support their children and families (Richter et al., 2012).

One participant echoed that:

"Mmmm, you see, my sister, when a woman faces difficult circumstances, she must find ways of surviving those difficulties. We all know that it is risky to do sex work and we cannot exactly say we are proud of what we do, but it is an option that some women must consider because they have families depending on them back in their home countries".

In the same breath, another participant stated that:

"I did not join the sex work industry, but I have friends who make a living out of sex work. Their experiences are unpleasant and sad but they continue because they have to make a living for themselves and their families back in Zimbabwe".

During a follow-up question with the participants, it was also revealed that some of these young migrants are vulnerable to sexual violence in South Africa however, they see it as an opportunity to make a living. The other participant gave the scenario of a man who asked for her services to do the house chores with an agreement to compensate her with money, but during the process of performing the required services, she was sexually violated. by the same man. This participant stated that even though how the man had sex with her was not appropriate, she had no option to report the abuse to the legal authorities because she was silenced with money thereafter and to her, she had found that as a way to make a living as a young female migrant in South Africa. This is what the participant said:

"Well, I remember the other time a certain man in the location called me and asked that I assist him in his house with cleaning and cooking and that he shall pay me. While I was busy working, the man demanded sex from me which I have found not appropriate because he had sex with me without my permission and we had to do it because he had promised to increase the money he was going to pay me. That helped me as I came out with a lot of money for myself and my family back home.

Upon a follow-up question on why such incidences of sexual violence were not reported to the police, the other participant indicated that even if they do report, the same legal officials also repeat the same action against them and would bribe them with money so they don't talk, which therefore helps them financially as it enables them to provide for their families. It is, however, unfortunate that being a migrant, a woman, and a sex worker also places migrant women selling sex at increased risks of human rights violations, including police abuse, arrest, detention, deportation, discrimination, xenophobic violence, and death.

This is what the participant echoed:

“What? You don't know. Things are happening here in South Africa. To be a woman is not only a disadvantage but sometimes it is an advantage. You get raped by a man and when you report that, the very same police officer calls you after and when you meet him he rapes you and gives you money, and to be honest that money helps us as we are starving here in South Africa". 
It can be noted from the above findings that although their involvement in sex work is often accompanied by sexual violence, young female migrants see it as an opportunity to make more money because they would be paid to keep quiet and not report the matter, thereby allowing them to send some money home and take care of themselves. These findings are therefore not new and unique, previous studies have also highlighted that there is a high proportion of the statistics of sex workers in South Africa perpetuated by the international migrants (Scorgie et al., 2013; Richter et al., 2013). It should also be noted that whilst these young female migrants resort to sex work to survive, some men, including law officials who are supposed to be enforcing the law and protecting them, also take advantage and violate their sexual rights. It is such an unfortunate circumstance that the victims of such horrible acts are not able to report these acts of criminality perpetrated against them merely because they make extra money from such incidences. Sadly, young female migrants are desperate for survival that they would agree to anything, even if it is a violation of their sexual rights. This inhumane and tragic was also discovered in several studies in South Africa that such crimes are even committed by law enforcement agents (Young, Boyd \& Hubbel, 2000; Rasangami et al., 2016; Snivurai et al., 2019). It can therefore be concluded that there is a tendency of gender-based violence against female international migrants in South Africa, unfortunately even by law officials, although to some of them the incidents serve as another way of survival.

\section{Theme 4: Exploitation by Local Citizens}

Participants in the study have highlighted that in their quest for survival in the host country, they are often exploited by the country's local citizens. Some participants further mentioned that local citizens take advantage of their desperation and the fact that the police would not even entertain them even if they are to report incidents of exploitation against them. The other participant mentioned that South Africans treat them with hostility because they want them to go back to their home countries. The participants further indicated that they are often exploited by their employers, who sometimes hire them for casual jobs such as household chores, also they often find themselves exploited by their customers in their informal selfemployment jobs who pay them little money for their services, knowing very well they won't say no as a result of their desperation for money. Bloch (2010) notes that the position of undocumented migrants in
South Africa is precarious and vulnerable. In their study, Idemudia, Williams, and Wyatt (2013) found that Zimbabweans left for South Africa expecting to find an abundance of opportunities and "a land flowing with milk and honey", unfortunately, the Zimbabwean migrants in South Africa are faced with a vast number of challenges including financial challenges, poor living conditions, unemployment and poverty, health care problems, and the lack of access to basic resources that were similar to what existed in Zimbabwe, not much has changed from their situation in their country of origin. The researchers have noted that most if not all of the expectations these female migrants had before migrating to South Africa have not yet been met and are saddened and disappointed by this fact as they had high hopes.

In support of the above, one participant said:

"Many people here in South Africa, when you work for her, they don't want to pay you, and they saw the Zimbabwean people as the poorest people in the world, so when you work with her, they can't tolerate you nicely I don't know why, so you just accept the little money they give you because we don't have a choice.."

Another participant added:

"Sometimes the employers shout at us, telling me that you are not cleaning you are wasting my money, and when you finish working, they give you small money and it not what you agreed on."

In the same wavelength, another participant echoed:

"When I'm talking about me, I plait hair. When a plaited hair, I will charge money like R50 maybe. What I want is money, sometimes after you finish their hair, she says I will give you R10 or R20, what can I do, I just take it and keep quiet, I have no choice because what I want is money."

It can be noted from the above findings that most migrants left their countries because of unfavourable conditions such as unemployment, coming to South Africa and still facing the challenge of unemployment makes them more vulnerable and exposes them to victimization and labour exploitation where they are paid less for every work they do, often go without pay from exploitative employers, thereby affecting their 
well-being and quality of life. From afar, they see South Africa as a country with a lot of opportunities, unfortunately, after their arrival and during their stay, things don't work out as they had hoped, therefore they turn to hairdressing, street vending, and casual jobs. It is in those jobs where they face continued exploitation from the country's local citizens. In support of this, Kanayo and Anjofui (2020) note that to deal with the reality of unemployment, most migrants resort to looking for other survival alternatives, for instance, selfemployment or picking up casual jobs such as cleaning, working in restaurants, security, working as domestic servants wherein they often face abuse and exploitation. The researchers have noted that, because of their continued desperation, these young female migrants accept and continue being exposed to such exploitation for as long as they will have little money at the end of the day to buy basic needs.

\section{Theme 5: Victimisation by the Police}

Participants have highlighted their unpleasant experiences with the South African police when they report their cases to them. Some participants indicated that whenever they would go to the police station to report cases of assault or other criminal activities instigated upon them, they would be treated negatively with so much stigmatisation and discrimination, and their cases would not be attended to. During the interviews, other participants have indicated that when they report cases such as domestic violence and exploitation in their respective places of work, the police would neglect their cases based on their lack of legal documents. Their cases would be left hanging and unattended as it is not a matter of urgency since the female migrants are non-nationals. In support, Khosravi (2010) adds that documentation matters for irregular migrants and affects their lives in numerous ways in destination countries. The researchers have observed that migrants in South Africa are without protection and therefore anything could happen to them with the police doing very little to curb the violence and criminal activities against female migrants. Additionally, the Amnesty International (Al) report of 2015 found that discrimination against African migrants is often being exhibited by the police officers as well; apparently, Zimbabweans frequently complain that they are targeted by criminals and harassed by the police in South African cities (Independent Online, 2007a). In support, the Amnesty International (AI) report of 2015 adds that discrimination against African migrants is often exhibited by police officers as well.
In support of the above, one participant echoed:

"Just when I was working in Tzaneen with other people from Zimbabwe when we were not paid our money by our boss who took advantage of us being foreigners and he threatened to put tyres around our necks and burn us, and the police said yes they will do so, and we just left without our money. The police did not even want to hear our story, we just left without any help from them."

In the same wavelength, another respondent said:

"Like some other time, I had an incident, a man came here and said he wants me to wash his clothes but when we went to his place, he just said no I want you to entertain me. But he became violent and started slapping me, so we ended up at the police and he told them that this girl stole my phone and the police said nothing, they just took me back to the shelter without doing anything."

Another participant added that:

"I was working on farms, and then I was staying with my husband and then he beat me and he poured me with boiling water, I got to the hospital and then I was discharged and I went to the police and to open a case and then we go there, we didn't find him, he runs away. The police then brought me here and left, since then, they did not do anything about my case and didn't go looking for him."

The study findings reveal that female migrants in South Africa are unprotected. Their undocumented status exposes them to hostile treatments in the hands of the police, who neglect their cases simply because they don't have legal documents. Further, the police appear to be racially insensitive as they discriminate against migrants based on their countries of origin, grounding their services solely on legal citizenship. Negative views about African migrants are particularly dangerous when held by the police as the treatments following such views could be threatening for migrants (Nyamnjoh, 2010). However, this does not come as much of a surprise - Centre for the Study of Violence and Reconciliation (CSVR) research in 2004 showed that only 35 percent of the South African Police Service 
had received 'some' training on race and discrimination, and that diversity training is largely seen as irrelevant to police work by station commanders (Palmary, 2004). There is extreme xenophobia in South Africa, which is directed against other Africans, as well as the extortion and victimisation of undocumented and other migrants by the police (Klaaren \& Ramji, 2001; Landau, Ramjathan-Keogh \& Gavatri, 2005). The police can hardly treat foreigners impartially if they do not understand their language or cultures and have no basic training in human rights. Being an undocumented young female migrant invites a lot of hate and negative treatment and leaves migrant women at risk of harm and criminal activities instigated upon them because they are without protection.

\section{CONCLUSIONS AND RECOMMENDATIONS}

The study findings reveal that female migrant youth coming to South Africa seeking better livelihoods are met with many difficulties and challenges in their everyday lives. The study found that the horrible experiences faced by young female migrants in South Africa are primarily a result of their nationality and legal status. It was also found that female migrant youth in South Africa are victimised and exploited by local citizens as well as government officials. Their lack of legal documentation exposes them to a variety of illtreatments and social exclusion in the hands of South Africans, starting from those who offer basic services such as police officers and health care professionals to local citizens. As a result, this negatively affects young female migrants' well-being and their successful adaptation and integration into the host country and its various communities. Therefore, to deal with the growing number of undocumented migrants illegally crossing into South Africa without valid permits, the security at the border post and areas where the migrants can illegally cross needs to be tightened, and have the police who will be deployed to secure and guard the area. Also, government officials need to have awareness of issues around culture and racial differences to curb the already existing hatred and discrimination towards foreigners highlighting their intense cultural and racial insensitivity. Although the migrants may not originate from South Africa, professionals such as healthcare workers need to be aware of the laws that are already in place that guarantee the right of access to healthcare for everyone, migrants included. Further research should be conducted on how the government plans to curb the influx of illegal migrants and what measures will be put in place. South Africans must adopt a culture of inclusiveness and a sense of acceptance towards African migrants.

\section{ACKNOWLEDGEMENTS}

The author is grateful to the National Research Foundation for its support.

\section{DECLARATION OF A CONFLICT OF INTEREST}

There is no conflict of interest in this article paper. All sources have been acknowledged.

\section{FUNDING SOURCE}

The authors declare that the publication of this paper received funding from the National Research Foundation with a grant number 116810 .

\section{REFERENCES}

Adjai, C. \& Lazaridis, G. (2013). Migration, xenophobia and new racism in post-apartheid South Africa. Int'l J. Soc. Sci. Stud., $1,192$.

https://doi.org/10.11114/ijsss.v1i1.102

Amnesty International (2015). Al slams government of South Africa for failing to stop xenophobia. Available at: http://www.enca.com/south-africa/Amnesty-Internationalslams-government-failing-stopxenophobia.

Bal, M. (2004). Narrative theory: critical concepts in literary and cultural studies.

Belvedere, F. Pigou, P. \& Handmaker, J. (2001). Realizing rights: The development of health and welfare policies for asylum seekers and refugees in South Africa. Commissioned by UNHCR, Published by CASE.

Bisrat WK (2014) International migration and its socioeconomic impact on migrant sending households evidence from Irob Woreda, Eastern zone of Tigray, Regional State. Master's thesis (Unpublished), Mekelle University, Ethiopia.

Black, R., J. Crush, S. Peberdy with S. Ammassari, L.M. Hilker, S. Mouillesseaux, C. Pooley and R. Rajkotia. (2006). Migration and Development in Africa: An Overview. Cape Town: Southern African Migration Project.

Bloch, A. (2010). The Right to Rights? Undocumented Migrants from Zimbabwe Living in South Africa. London: City University. https://doi.org/10.1177/0038038509357209

Crush J and Tawodzera, G. (2014) Medical xenophobia and Zimbabwean migrant access to public health services in South Africa. Journal of Ethnic and Migration Studies 40(4): 655-670. https://doi.org/10.1080/1369183X.2013.830504

De Vos, A., Strydom, H., Fouche, C. and Delport, C. (2011) Research at Grass Roots: For Social Sciences and Human Services Professions. Van Schaik Publishers, Pretoria.

Hammarberg K, Kirkman, M \& de Lacey, S. (2016). Qualitative research methods: When to use them and how to judge them. Human Reproduction 31(3): 498-501. https://doi.org/10.1093/humrep/dev334

Hiralal, K. (2015). Migration and education narratives of student mobility in South Africa. The Oriental Anthropologist 15(2): 331-344

HSRC (2010). Violence and xenophobia in South Africa: Developing consensus, moving to action. Available at: http://www.queensu.ca/samp/migrationresources/hadland.pdf 
HRW (2015). South Africa. Available at: http://www.hrw.org/worldreport/2015/country-chapters/southafrica.

Idemudia E. S. Williams J, K. \& Wyatt, G.E. (2013). Migration challenges among Zimbabwean refugees before, during and post arrival in South Africa. https://doi.org/10.5249/jivr.v5i1.185

Independent Online (2007a). 'South Africa becoming a nation of xenophobes' 29 January 2007 < http://www.iol.co.za/>.

Kanayo, O. and Anjofui, P. (2021). Migration Dynamics in Africa: Expectations and Lived Experiences of Immigrants in South Africa. Journal of Asian and African Studies, 56(3), pp.572588. https://doi.org/10.1177/0021909620934840

Khosravi, S. (2010). "Illegal" traveler. An auto-ethnography of borders. Global ethic series. Great Britain: Palgrave MacMillan. https://doi.org/10.1057/9780230281325

Klaaren, J. \& Ramji, J. (2001). 'Inside Illegality: Migration Policing in South Africa after Apartheid'. Africa Today 48(3): 35-47. https://doi.org/10.1353/at.2001.0054

Landau, L. K. Ramjathan-Keogh \& Gavatri, S. (2005). Xenophobia in South Africa and problems related to it. Forced Migration Working Paper Series No. 13. University of the Witwatersrand, Forced Migration Studies Programme.

McDonald D.A. (2000). Introduction: Towards a better understanding of cross-border migration in Southern Africa. In: McDonald D.A. (ed.), On Borders: Perspectives on International Migration in Southern Africa, pp. 1-11. St. Martin's Press, New York.

Miles, M. B., \& Huberman, A. (2014). M., \& Saldana, J. (2014). Qualitative data analysis: A methods sourcebook, 3.

Nyamnjoh, F.B. (2010). Racism, Ethnicity and the Media in Africa: Reflections Inspired by Studies of Xenophobia in Cameroon and South Africa, in Africa Spectrum, 45, 1, 57-93. https://doi.org/10.1177/000203971004500103

Oppong, C. (1997). African family systems and socio-economic crisis.

Pasura, D. (2008). Gendering the Diaspora: Zimbabwean Migrants in Britain La question du genre dans la diaspora: les migrants zimbabwéens en Grande-Bretagne. African Diaspora, 1(1-2), 86-109. https://doi.org/10.1163/187254608X346060

Palmary, I. (2004) Refugees, Safety and Xenophobia in South African Cities: The Role of Local Government, CSVR

Rapholo, S.F., (2020), 'Perceptions of church leaders on the integration of migrant youth into South Africa: The case of refugees in the refugee camps managed by churches at Musina', Theologia Viatorum 44(1), a34. https://doi.org/10.4102/TV.v44i1.34

Randolph, C.K., (2012) The conflict surrounding universal access to HIVIAIDS medical treatment in South Africa. Human Rights Brief 19(2): Art.5.
Rangasami, J., Konstant, T., \& Manoek, S. (2016). Police Abuse of Sex Workers: Data from cases reported to the Women's Legal Centre between 2011 and 2015; Women's Legal Centre.

Richter, M., Luchters, S., Ndlovu, D., Temmerman, M. and Chersich, M.F., (2012). Female sex work and international sport events-no major changes in demand or supply of paid sex during the 2010 Soccer World Cup: a cross-sectional study. BMC public health, 12(1), pp.1-12. https://doi.org/10.1186/1471-2458-12-763

Richter, M., Chersich M.F., Temmerman M. \& Luchters, S. (2013) Characteristics, sexual behaviour and risk factors of female, male and transgender sex workers in South Africa. South African Medical Journal, 103(4), 246-251. https://doi.org/10.7196/SAMJ.6170

Scorgie, F., Vasey, K., Harper, E., Richter, M., Nare, P., Maseko, S., \& Chersich, M. F. (2013). Human rights abuses and collective resilience among sex workers in four African countries: a qualitative study. Globalization and health, 9(1), 33. https://doi.org/10.1186/1744-8603-9-33

Serumaga-Zake, P. A., \& Unisa, S. B. L. (2017). Migration and tourism: The challenges of Zimbabwean diaspora in South Africa. African Journal of Hospitality, Tourism and Leisure, 6(4), 1-20.

Shai, K. B., \& Mothibi, K. A. (2015). Describing pre-2009 xenophobic violence in South Africa: A human right perspective. The xenophobic attacks in South Africa: reflections and possible strategies to ward them off, 261.

Shea, L. (2009). Professional migrants in Cape Town: Identity, culture and community. Doctoral dissertation, University of South Africa, South Africa.

Svinurai, A., Makhubele J.C., Ananias J.A., Freeman R.J., Mafa, P., Matlakala F.K., Chilwalo B.N., Rapholo S.F., Hamuse, T. N.I \& Hasheela, M. W. (2019). 'You cannot be Raped when you are a Sex Worker': Sexual Violence among Substance Abusing Sex Workers in Musina, Limpopo Province. e-Bangi, 16(4).

Statistics, S. A. (2018). Statistical release P6242. 1. Pretoria: Statistics SA.

Tati, G. (2010). Student migration in South Africa: A special reference to youth francophone Africa. Espace Populations' Societies 2(3): 281-298. https://doi.org/10.4000/eps.4160

Van Tonder, C.L., \& Soontiens, W. (2013). Migrants: First work encounters. Procedia-Social and Behavioral Sciences 82: 466-476. https://doi.org/10.1016/j.sbspro.2013.06.294

Young, A.M., Boyd, C. and Hubbell, A. (2000). Prostitution, Drug Use, and Coping with Psychological Distress, Journal of Drug Issues 30(4), 789-800. https://doi.org/10.1177/002204260003000407 